\title{
Morbidity and mortality associated with emergency obstetric hysterectomy: a three year retrospective study in a tertiary care centre of India
}

\author{
Swati $^{1}$, Vineeta ${ }^{2}$, Ahmad Nadeem Aslami ${ }^{3 *}$
}

\begin{abstract}
${ }^{1}$ Department of Obstetrics and Gynecology, JLN Medical College and Hospital, Ajmer, Rajasthan, India
${ }^{2}$ Department of Obstetrics and Gynecology, ${ }^{3}$ Department of Community Medicine, NMCH, Sasaram, Bihar, India
\end{abstract}

Received: 26 July 2018

Accepted: 04 August 2018

\author{
*Correspondence: \\ Dr. Vineeta, \\ E-mail: vineeta.rims@gmail.com
}

Copyright: (C) the author(s), publisher and licensee Medip Academy. This is an open-access article distributed under the terms of the Creative Commons Attribution Non-Commercial License, which permits unrestricted non-commercial use, distribution, and reproduction in any medium, provided the original work is properly cited.

\begin{abstract}
Background: Emergency obstetric hysterectomy $(\mathrm{EOH})$ continues to remain an important life saving procedure in the era of modern obstetrics. EOH acts as a near miss marker as a proxy for maternal mortality. The objective of this study was to analyze $52 \mathrm{EOH}$ done in a tertiary care centre of Ajmer, Rajasthan, India.

Methods: A retrospective study was done using hospital records of $52 \mathrm{EOH}$ done in a three year period in the Department of Obstetric and Gynaecology, LNJ Medical College, Ajmer, Rajasthan, India.

Results: The incidence of obstetric hysterectomy was 1.25 in 1000 deliveries. The average age of the patients was 27.8 years. Most common reason for EOH was post partum haemorrhage (PPH). $86.5 \%$ patients went under subtotal hysterectomies. Several complications occurred in these patients, severe anemia being most common. $28.8 \%$ patients died after the operations. More than half patients delivered a live baby while $40.4 \%$ had still births.

Conclusions: $\mathrm{EOH}$ is a life saving procedure. The outcome depends on timely decision and apt clinical judgement because delay can lead to high maternal as well as infant mortality.
\end{abstract}

Keywords: Anemia, Emergency obstetric hysterectomy (EOH), Near miss, Post partum haemorrhage (PPH)

\section{INTRODUCTION}

Emergency obstetric hysterectomy is defined as extirpation of the uterus either at the time of caesarean section or following vaginal delivery, or within the puerperium period. A near miss event is defined as women who nearly died but survived a complication that occurred during pregnancy, childbirth, or within 42 days of termination of pregnancy. ${ }^{1} \mathrm{EOH}$ can be rightly classified as a near miss event and can act as a 'near miss' marker for maternal mortality. ${ }^{2}$

$\mathrm{EOH}$ is sometimes a life saving procedure. It is a very essential skill for any obstetrician although it is used as a last resort to save the life of the mother thus sacrificing her reproductive capability. Often it is a difficult decision and requires timely clinical judgement. ${ }^{3}$

A WHO systematic analysis showed that worldwide, $27.1 \%$ of maternal deaths are attributed to haemorrhage. India and Nigeria accounted for a third of these global maternal deaths. ${ }^{4} \mathrm{EOH}$ is a most demanding obstetric surgery performed in very trying circumstances of life threatening haemorrhage. When conservative treatment has failed or is not feasible, immediate $\mathrm{EOH}$ is performed failing which the delay would contribute to the maternal morbidity and in unfortunate case mortality. ${ }^{5}$

The incidence of $\mathrm{EOH}$ is $0.05 \%$ worldwide with considerable difference in different parts of the world. A 
systematic review of 82 studies from 46 countries between 2014 and 2010 showed that EOH rates have increased by $8 \%$ per year. $^{6}$

\section{METHODS}

A retrospective analysis of 52 cases of emergency obstetric hysterectomy performed between January 2014 and December 2016 was done. The study was carried out in the department of obstetrics and gynecology of the Rajkiya Mahila Chikistalaya and JLN Medical College in Ajmer, Rajasthan, India.

All women who delivered outside the hospital and were referred for obstetric complications meriting a hysterectomy were also included in the study. Women who delivered before 24 weeks of gestation, undergoing hysterectomy for causes other than obstetric or who came after 42 days of delivery were excluded from the analysis. ${ }^{1}$

Data of the patients were collected from medical records department after adequate clearance from institutional ethical committee, and the data of all the cases were kept confidential.

Data was studied for maternal profile including age and parity, indications for hysterectomy, postoperative complications and fetal outcomes. Data was analysed and compiled by Microsoft excel 2007 and epiinfo 7.1.1.4 software freely available on internet. For statistical significance, confidence interval was considered $>95 \%$ ( $p$ value $\leq 0.05)$.

\section{RESULTS}

There were 52 cases of obstetric hysterectomies during the three year of the study period amongst 41470 deliveries during the same period. The incidence of obstetric hysterectomy in this study was $0.12 \%$ i.e. 1.25 in 1000 deliveries. The majority of patients belonged to rural areas $(76.9 \% ; 40 / 52)$, of low socio-economic status $(71.1 \% ; 37 / 52)$ and were illiterate $(55.8 \% ; 29 / 52)$.

Table 1: Distribution of obstetric hysterectomy cases according to age and parity.

\begin{tabular}{|llllll|}
\hline Age (years) & 0 & 1 & 2 & $>2$ & Total \\
\hline$<21$ & 2 & 0 & 0 & 0 & 2 \\
\hline $21-25$ & 2 & 6 & 4 & 2 & 14 \\
\hline $26-30$ & 0 & 5 & 12 & 7 & 24 \\
\hline $31-35$ & 0 & 0 & 4 & 5 & 9 \\
\hline$>35$ & 0 & 0 & 1 & 2 & 3 \\
\hline Total & 4 & 11 & 20 & 16 & 52 \\
\hline (Mean \pm SD) & $27.8 \pm 3.94$ & years & & \\
\hline Variance & 13.21 years \\
\hline Chi square value & 38.6 & \\
\hline p value & \begin{tabular}{l} 
significant) \\
\hline
\end{tabular}
\end{tabular}

Table 1 shows distribution of cases according to age and parity of patients. The minimum age of women who went for obstetric hysterectomy was 20 years while the maximum age was 37 years with a mean age of 27.8 years and standard deviation of 3.94 years. In present study, the most common $(46.2 \% ; 24 / 52)$ age group of patients who went for obstetric hysterectomy was between 26-30 years. In relation to parity of the cases, only $4(7.7 \%)$ were nulliparous out of 52 cases. $21.2 \%$ $(11 / 52)$ of cases were primiparous while $69.1 \%(36 / 52)$ were multiparous.

Table 2: Indications for obstetric hysterectomy $(n=52)$.

\begin{tabular}{|lll|}
\hline Indications & Number of cases & Percentages \\
\hline Atonic PPH & 18 & 34.6 \\
\hline $\begin{array}{l}\text { PPH due to } \\
\text { placental causes }\end{array}$ & 14 & 26.9 \\
\hline Ruptured uterus & 16 & 30.8 \\
\hline $\begin{array}{l}\text { As complication } \\
\text { of abortion }\end{array}$ & 3 & 5.8 \\
\hline $\begin{array}{l}\text { Perforation during } \\
\text { PPIUCD removal }\end{array}$ & 1 & 1.9 \\
\hline
\end{tabular}

Table 2 shows various indications for obstetric hysterectomies. In present study major indication for obstetric hysterectomies was post partum haemorrhage (PPH), which was indicated in $61.5 \%(32 / 52)$ cases. Out of 52 cases of obstetric hysterectomies, $34.6 \%$ were due to atonic PPH and $26.9 \%$ were because of PPH related to placental causes. Subtotal hysterectomies were performed in $86.5 \%(45 / 52)$ of cases while remaining $13.5 \%(7 / 52)$ underwent total hysterectomy.

Table 3: Postoperative maternal complications $(\mathrm{N}=52)$.

\begin{tabular}{|lll|}
\hline Causes & Cases* $^{*}$ & Percentages \\
\hline Severe anemia & 16 & 30.77 \\
\hline Pyrexia & 8 & 15.38 \\
\hline $\begin{array}{l}\text { Bladder and renal } \\
\text { complications }\end{array}$ & 7 & 13.46 \\
\hline Paralytic ileus & 6 & 11.54 \\
\hline DIC & 5 & 9.62 \\
\hline Wound sepsis & 4 & 7.69 \\
\hline Deaths & 15 & 28.85 \\
\hline
\end{tabular}

*Total is more than 52 as few patient had more than one complications

Table 3 depicts post-operative maternal complications after obstetric hysterectomy. Severe anemia was seen as most common morbidity in approximately one third $(30.7 \%)$ of the cases. This was followed by pyrexia (15.4\%), bladder and renal complications (13.5\%), paralytic ileus $(11.5 \%)$, DIC $(9.6 \%)$ and wound sepsis $(7.7 \%)$. Fifteen women died after the procedure. So, the prevalence of maternal mortality was $28.8 \%$. Most of these deaths were attributed to blood loss. Blood transfusion was done in all 52 cases either intra- 
operatively or post-operatively. $61.5 \%(32 / 52)$ patients needed ICU admission in post-operative period.

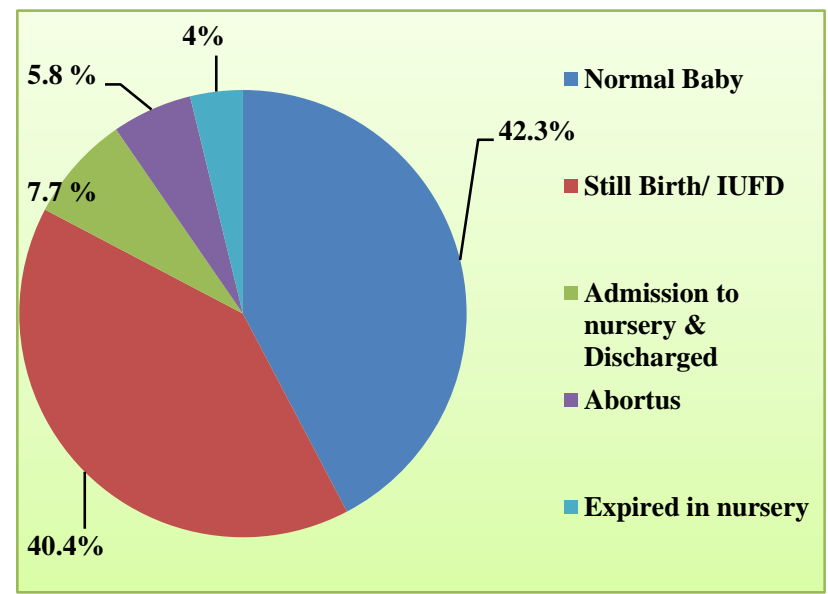

Figure 1: Prevalence of fetal outcomes.

Figure 1 shows the fetal outcomes in our study subjects. Out of 52 delivered cases, $42.31 \%$ babies were normal. $28(53.8 \%)$ patients delivered a live child, out of these, 6 were admitted to nursery but only 4 survived in nursery and two died later. The prevalence of still birth in this study was $40.4 \%$.

\section{DISCUSSION}

JLN hospital is a 300 bedded tertiary care centre in Ajmer, Rajasthan which receives referrals from several nearby rural centres in addition to serving patients from local urban areas. The study was important as it provided an insight into the standard of obstetric health care available to the nearby rural and urban population.

The overall incidence of EOH during three-year period covered in this study was $0.125 \%$. Incidence in this study is very similar to studies done by Shirodker SD et al and Mayadeo NM et al. ${ }^{7,8}$ Although the incidence is higher than many other studies done in developed countries and in India because this institution is an important referral centre in this region and most $(59.6 \% ; 31 / 52)$ of these cases were referred from outside centres in moribund condition after complications have already occurred.9-11

However incidence of EOH was as high as $0.54 \%$ and $0.37 \%$ in studies done by Singh et al and Sharma et al, respectively. ${ }^{12,13}$ The incidence in this study is low in comparison to usual incidence of Asian mothers as shown in a study done by Huque et al during world maternal anti-fibrinolytic (WOMAN) trail done in 21 countries of Asia and Africa. ${ }^{14}$ This highlights the improvement in delivering of health facility and strengthening of health system infrastructure, which resulted in less incidence of $\mathrm{EOH}$ in our region.

This study finds the incidence of $\mathrm{EOH}$ to be $0.116 \%$ following vaginal delivery and $0.113 \%$ following cesarian delivery. This shows that mode of delivery had little impact on the rate of $\mathrm{EOH}$ in this region. This finding is different from other studies showing that the incidence of $\mathrm{EOH}$ was more frequent after caesarean section than that after vaginal delivery, nine times by Chawla et al $(0.270 \%$ vs $0.030 \%), 3.85$ times by Singh et al $(2.08 \%$ vs $0.54 \%)$ and 1.6 times by Carvalho et al (8 vs 5 out of 13). ${ }^{1,12,15}$ Caesarean section results in scarring of uterus which predisposes to abnormal placentation. The main indication of $\mathrm{EOH}$ has shifted in recent decade from uterine atony to placenta accrete, in conjunction with a rise in caesarean delivery rates. ${ }^{9,10}$

Atonic PPH not responding to drugs and conservative surgeries was the most common indication in this study $(34.62 \%)$ and also in the study conducted by Carvalho et al. ${ }^{15}$ Post-operative morbidities and mortalities were not due to procedure itself but were due to the result of massive bleeding, which led to shock-related complications, decreased immunity and other comorbidities. The mortality in this study was $28.8 \%$, although it ranged $5-18 \%$ in other studies. ${ }^{1,12,13}$ The high mortality rate may be related to the characteristics of our hospital as a referral hospital. The patients reported to our hospital in critical conditions, and $\mathrm{EOH}$ was performed as a last resort to save their lives. The mean of distance of all the rural health centres was calculated as 63 kilometres. The poor condition of roads connecting these centres to our hospital was an additive factor leading to delay in reporting of these referred patients to our hospital.

\section{CONCLUSION}

Even in an era of modern obstetrics, EOH holds its fort as a last resort to decrease near miss morbidity and save the life of the mother. However, incidence of EOH can be reduced with better implementation of the Government's maternal health services, good ante-natal care at the peripheral level, proper intra-partum management of labour and timely and judicious performance of caesarean section.

\section{Funding: No funding sources}

Conflict of interest: None declared

Ethical approval: The study was approved by the Institutional Ethics Committee

\section{REFERENCES}

1. Chawla J, Arora D, Paul M, Ajmani SN. Emergency Obstetric Hysterectomy: A Retrospective Study from a Teaching Hospital in North Teaching Hospital in North India over Eight Years. Oman Med J. 2015;30:181-6.

2. Maswani S, Buchmann E. A Systematic review of maternal near miss and mortality due to postpartum hemorrage. Int J Gynaecol Obstet. 2017;137:1-7. 
3. Indulekha A, Divyaganga V, Yaakub R. Peripartum hemorrage in RIPAS hospital: experience over an 11 year period. Brunei Int Med J. 2012;8:122-7.

4. Say L, Chou D, Gemmil A, Tuncalp O, Moller AB, Daniels J. Global causes of maternal death: a WHO systematic analysis. Lancet Glob Health. 2014;2:e323-33.

5. Machado LSM. Emergency peripartum hysterectomy: Incidence, indications, risk factors and outcome. N Am J Med Sci. 2011;3:358-61.

6. Tuncalp O, Hindin MJ, Souza JP, Chou D, Say L. The prevalence of maternal near miss: a systematic review. BJOG. 2012;119:653-61.

7. Shirodker SD, Pandey A, Yadav S. Emergency obstetric hysterectomy: review at a tertiary care hospital. Int J Reprod Contracept Obstet Gynecol. 2016;5:3811-4.

8. Mayadeo NM, Swaminathan G. Obstetric hysterectomy: analysis of 50 cases at a tertiary care hospital. Int J Reprod Contracept Obstet Gynecol. 2018;7:2882-7.

9. Flood KM, Said S, Geary M, Robson M, Fitzpatrick $\mathrm{C}$, Malone FD. Changing trends in peripartum hysterectomy over the last 4 decades. Am J Obstet Gynecol. 2009;200:632.e1-6.

10. Temizkan O, Angin D, Karakus R, Sanverdi I, Polat M, Karateke A. Changing trends in emergency peripartum hysterectomy in a tertiary obstetric center in Turkey during 2000-2013.J Turk Ger Gynecol Assoc. 2016;17:26-34.
11. Praneshwari Devi RK, Singh N, Singh D. Emergency Hysterectomy: A study of 26 cases over a period of 5 yeras. J Obstet Gynecol. 2004:54:3435 .

12. Singh N, Pandey K, Gupta R, Agarwal S, Chaudhari A, Ani. Obstetric hysterectomy, still a life saving tool in modern day obstetrics: a five year study. Int J Reprod Contracept Obstet Gynecol. 2014;3:540-3.

13. Sharma B, Saxena N, Gupta V. A retrospective study of emergency obstetric hysterectomy in a tertiary care center for a period of 5 years. Int $\mathbf{J}$ Reprod Contracept Obstet Gynecol. 2016;5:3778-81.

14. Huque S, Roberts I, Fawole B, Chaudhri R, Arulkumaran S, Shakur-Still H. Risk factors for peripartum hysterectomy among women with postpartum hemorrhage: analysis of data from WOMAN trial. BMC Pregnancy Childbirth. 2018;18:186.

15. Carvalho JF, Cubal A, Torres S, Costa F, da Carmo O. Emergency peripartum hysterectomy: a 10- year review. International Scholarly Research Network Emergency Medicine, 2012. Available at http://www.hindawi.com/journals/isrn/2012/721918/.

Cite this article as: Swati, Vineeta, Aslami AN. Morbidity and mortality associated with emergency obstetric hysterectomy: a three year retrospective study in a tertiary care centre of India. Int J Reprod Contracept Obstet Gynecol 2018;7:3534-7. 